\title{
The Influence of COVID-19 on Physical Activity, Sleep Quality, and the Quality of Life in Adults by Age Group
}

\author{
Tae-Yeon Kim, Sil-Ah Choi \\ Department of Physical Therapy, Ansan University, Ansan, Republic of Korea
}

Purpose: The purpose of this study was to identify changes in physical activity, sleep quality, and quality of life (QOL) during COVID-19 in adults by age group.

Methods: An online survey was conducted on a total of 160 participants who were divided into three groups by age; young adults, middle-aged adults, and old adults. The participants responded to the self-reported assessment of the impact of social distancing during COVID-19, International Physical Activity Questionnaire (IPAQ), Pittsburgh Sleep Quality Index (PSOI), and Short Form-36 Health Survey (SF36). Descriptive statistics, analysis of variance, and Pearson's correlation were used for data analysis.

Results: There were significant differences between the three age groups in physical activity $(p<0.05)$ and PSOI $(p<0.01)$ and a post hoc analysis showed that the young adults' group had significantly higher physical activity than the old adults' group, while the old adults' group had significantly lower scores of PSOI (better sleep quality) than the others. The young adults' group showed a significant negative correlation between the stress from social distancing and QOL $(r=-0.27, p<0.05)$ and between PSOI and QOL $(r=-0.48, p<0.05)$. For the middle-aged adults' group, there was a significant negative correlation between PSOI and QOL $(r=-0.53, p<0.05)$. The old adults' group showed a significant negative correlation between the stress from social distancing and physical activity $(r=-0.35, p<0.05)$ and PSOI $(r=-0.50, p<0.05)$, while there was a significant positive correlation between physical activity and PSOI $(r=0.30, p<0.05)$ and QOL $(r=0.30, p<0.05)$.

Conclusion: The results of this study could be used as basic data for the promotion of physical and mental health in the post-COVID-19 era.

Keywords: COVID-19, Physical activity, Quality of life, Sleep quality, Social distancing

\section{서 론}

코로나바이러스감염증-19 (코로나19)는 중국 우한에서 2019년 11월 처음 보고된 이후, 중국과 가까운 국가뿐만 아니라, 전 세계로 확산되 었다. 코로나 19 의 주된 감염경로는 감염자의 비말이 호흡기나 눈 코·입의 점막으로 침투될 때 전파되는 것으로 알려져 있다. 감염이 되 면 평균 5-7일의 잠복기를 거친 뒤, $37.5^{\circ}$ 이상의 발열 및 기침이나 호 흡곤란 등의 호흡기 증상과 폐렴이 주증상으로 나타난다. 우리나라 는 2020년 1월 20일 최초 확진자 이후, 확진자 수가 꾸준히 증가하고 있는 추세이다. 특히, 2021년 7월 7일부터 확진자 수가 1,000명대로 급 격히 증가하였고, 이후에도 3 일 이상 1,000 명대로 확산세를 보여 2021 년 8월 19 일 기준 누적 확진자 수 230,808 명, 격리해제자 201,235 명 (88.57\%), 사망자 2,191 명(치명률 $1.12 \%)$ 으로 보고되었다.
우리나라에서는 코로나19 발생 이후 마스크 착용, 손 씻기, 기침예 절, 소독 및 환기 등의 일상생활 속에서의 예방수칙을 강조하고 있으 며, 국가적 차원에서는 사회적 거리두기의 단계화 및 코로나 19 백신 도입 등의 대응체계를 갖추고 있다. 특히 사회적 거리두기는 비약물 적인 방법으로 호흡기계 바이러스의 확산 및 감염력을 감소시킬 수 있는 효과적인 방법임이 입증되어 왔는데, ${ }^{4,5}$ 이는 모든 사회구성원 간의 물리적인 접촉을 최소화하는 것을 강력하게 요구한다. 우리나 라는 확진자 수가 1,000 명대로 진입하자 수도권을 대상으로 사회적 거리두기를 최고단계인 4단계로 격상하였고 이것은 인원 제한 및 모 임 금지를 넘어 실질적으로 모든 외출을 금지하는 것을 의미한다.

이렇듯 코로나 19 의 확산을 감소시키기 위한 방법으로 사회적 거리 두기가 철저히 시행되면서 우리는 '포스트 코로나(post corona)라는 새로운 시대를 맞이하고 있다. 포스트 코로나 시대의 가장 큰 특징은 
사람 대 사람의 만남보다 비대면 및 무인 방식을 선호하기 시작하면 서 경제, 사회, 문화, 교육, 의료 등의 다양한 분야에서 인터넷 활용을 통한 '언택트(untact: un+contact의 합성어)' 서비스를 적용하고 있다 는 것이다. ${ }^{6}$ 이러한 변화들을 연령대별로 살펴보면, 초.중.고등학교 부터 대학교까지의 청소년과 청년 학생들은 교육방송, 온라인 실시 간 수업, 강의 녹화 업로드 등의 방식으로 원격수업을 받고 있으며, 경제·사회활동을 하는 청년 및 중장년들은 메신저, 원격PC제어, 화 상회의 플랫폼 등을 활용하여 재택근무를 적극적으로 활용하고 있 다. ${ }^{8}$ 노인들의 경우에는 코로나 19 이후 인공지능 및 사물인터넷 등의 기술이 접목된 노년공학분야의 획기적인 발전을 통해 원격의료 및 비대면 돌봄 서비스를 지원받을 수 있게 되었다.9,10 이 외에도 온라인 쇼핑 및 배달, 무인 매장과 카페에서의 소비가 급증하였고, 인터넷.스 마트폰 게임, 온라인 스트리밍 공연, 홈트레이닝 등과 같은 실내활동 을 통한 여가생활이 일상화되었다.11-13

하지만 포스트 코로나로 인한 다양한 분야에서의 변화된 환경은 공통적으로 외부 활동의 규제 및 인간관계 단절이라는 부정적인 측 면을 가져와 신체적. 정신적인 문제를 야기할 수 있다는 것을 간과해 서는 안 된다. 아동. 청소년들은 장기화된 온라인 수업으로 인해 앉아 서 활동하는 시간이 급격히 증가하여 체력이 낮아지고, 비만이 증가 하였다. ${ }^{14}$ 신체적인 문제뿐만 아니라 아동들은 성인에 비해 집착, 산 만함, 짜증과 과민함, 두려움, 불면증 등의 심리적 문제와 문제행동은 심각한 것으로 나타났다. ${ }^{15}$ 또한 청년. 중장년층들은 재택근무 등으 로 인해 생산적 활동은 줄어드는 반면 온라인 활동은 증가되어 이로 인한 근골격계 문제들도 나타난다. 실제로 코로나19로 인한 스트레 스가 목과 허리의 통증과 상관성이 있다는 연구결과도 보고되었다. ${ }^{16}$ 재택근무로의 전환은 좌식근무 시간을 증가시켜 이는 체력 저하뿐 만 아니라, 근력 약화, 유연성 약화, 골밀도 감소 등을 야기시켰다. ${ }^{17}$ 그 리고 증가된 좌식 생활은 신체 불균형과 비만에 의한 심혈관계 질환 유발을 증가시킬 수 있고 ${ }^{18}$ 사망률 증가와 연관성이 있을 뿐만 아니 라, 만성질환이 생길 수 있다는 연구가 보고되었다. ${ }^{19}$ 그리고 고용상 태의 변화는 심리적 스트레스와 밀접한 관계가 있는데, ${ }^{20,21}$ 보건복지 부의 통계결과에 따르면 코로나 19 이후 우울증의 경우, 우울 평균점 수는 5.7점으로 2018년에 실시된 조사결과인 2.3점에 비해 2배 이상 증가하였고, 현재도 꾸준히 상승하고 있는 추세이다.22 노인들은 코로 나19로 인해 노인맞춤돌봄서비스는 중단되어 전화상으로 안부 확인 을 하고, 요양병원의 경우엔 코호트 격리. 외부인 출입금지로 가족과 의 면회가 어려워지게 되었다. ${ }^{23}$ 이러한 상황이 지속되면서 코로나 19 는 삶이 고독하고, 죽음에 임박한 노인들에게 불안과 우울 증상을 극 대화시키는 상황에 처하게 했다. ${ }^{24}$

이처럼 다양한 연령의 사람들이 '포스트 코로나라는 새로운 시대 속에서 신체적. 정신적 건강에 큰 변화를 겪고 있음에도 불구하고 이
에 대한 연령계층별 분석은 부족한 실정이다. 또한 신체활동량, 수면 의 질, 삶의 질 관련요인은 각 연령계층별로 상이한 생활방식 및 경제 활동 등으로 인해 차이가 있을 수 있다. 따라서 본 연구는 우리나라 국민의 신체활동량 및 경제활동 등의 특성을 고려한 자료를 중심으 로, ${ }^{25,26}$ 연령대를 20-30대(성인초기, young adults), 40-50대(성인중기, middle-aged adults), 60대 이상(성인후기, old adults)의 세 그룹으로 나 누어 각 연령계층별 코로나 19 로 인한 신체활동량, 수면의 질, 삶의 질 의 변화를 비교하고, 사회적 거리두기로 인한 스트레스와의 상관관 계를 분석하고자한다.

\section{연구 방법}

\section{1. 연구대상}

본 연구는 설문 당시 전국에서 시행되고 있는 사회적 거리두기 4단계 인 점을 감안하여 비대면으로 진행하였다. 연령계층별로 20-30대, 40-50대, 60대 이상을 대상으로 구글 폼을 이용한 온라인 설문지를 제공하였다. 해당 설문은 연구자들이 사회적 관계망 서비스를 통하 여 본 연구의 취지와 목적에 대해 설명을 한 뒤 연구대상자의 동의를 받아 설문을 진행하였다. 설문기간은 2021년 7월 26일부터 8월 4일까 지로 총 10 일간 실시하였고, 배포한 설문지 총 160 부 중 미응답 및 불 성실한 응답 없이 총 160 명에 대한 설문지를 대상으로 분석을 하였다.

\section{2. 실험방법}

1) 측정도구

(1) 코로나19로 인한 사회적 거리두기 자가 평가

(1) 사회적 거리두기 준수 정도

선행연구를 바탕으로 코로나 19 로 인한 사회적 거리두기 준수 정도는 '잘 지키고 있다., '가끔 벗어날 때도 있다(주 $1 / 2$ 회).' '잘 지키지 않는다.' 의 세 가지 문항으로 분류하여 주관적으로 응답하도록 하였다. ${ }^{27}$

\section{(2) 사회적 거리두기 스트레스 평가} 코로나19로 인한 사회적 거리두기에 대한 스트레스 정도를 파악하기 위해 선행연구를 참고하여 시각적 사상 척도(Visual Analogue Scale, $\mathrm{VAS}$ )를 사용하였다. ${ }^{27} \mathrm{VAS}$ 는 0 부터 10 까지 표시된 선 위에 자신이 느 끼는 스트레스 강도를 직접 표시할 수 있는 주관적인 통증 척도이다. 0 점은 스트레스가 전혀 없는 상태, 10 점은 심한 스트레스를 받고 있 는상태를 의미한다.

\section{(2) 신체활동량}

신체활동량을 측정하기 위해 세계보건기구에서 개발한 단문형 국제 신체활동 설문지(International Physical Activity Questionnaire, IPAQ) 
의 한국어 번역판을 사용하였다. ${ }^{28}$ 단문형 IPAQ는 지난 7일간의 활동 량을 측정하는 설문지로, 10 분 이상 시행한 고/중강도 각각의 신체활 동에 대한 소비 횟수와 시간, 앉아서 보낸 시간, 걷는 시간 등이 포함 되어 총 7문항으로 구성되어 있고 각 신체활동 강도별로 적절한 예시 가 제시되어있다(고강도 신체활동: 무거운 물건 나르기, 에어로빅, 달 리기 등 중강도 신체활동: 가벼운 물건 나르기, 보통 속도로 자전거 타기 등). 신체활동량을 계산하는 방법은 범주형과 연속형 두 가지가 있는데, 본 연구에서는 연속형 계산방법으로 신체활동량을 평가하 였다. 연속형 점수는 3 단계 신체활동(걷기, 중강도, 고강도)의 Metabolic Equivalent of Task (MET) 수준 $\times$ 시행 기간(분)×주당 횟수로 계 산하며, 단위는 MET-min/week이다. 총 신체활동량은 모든 3단계 신 체활동의 점수를 합산한다. ${ }^{29}$ 산출공식은 다음과 같다.

(1) 걷기 $=3.3 \mathrm{METs} \times$ 걸은 시간 $($ 분 $) \times$ 걸은 일수

(2) 중강도 $=4.0 \mathrm{METs} \times$ 중강도 활동시간(분) $\times$ 중강도 활동일수

(3) 고강도 $=8.0 \mathrm{METs} \times$ 고강도 활동시간(분 $) \times$ 고강도 활동일수

(4) 총 신체활동량 $=$ 걷기 + 중강도 + 고강도

(3) 수면의 질

수면의 질을 측정하기 위해 Buysse 등 ${ }^{30}$ 이 개발한 Pittsburgh Sleep Quality Index (PSQI)를 한국어로 번역한 한국어판 피츠버그 수면의 질 지수(Korean version of the Pittsburgh Sleep Quality Index, PSQI-K) 를 사용하였으며, PSQI-K의 Cronbach's $\alpha$ 값이 0.84 로 신뢰도가 검증 되었다. ${ }^{31}$ 본 도구의 하부 영역별 항목은 지난 한달 동안의 주관적인 수면의 질, 수면 잠복기, 수면 시간, 평소의 수면 효율성, 수면 방해, 수 면제의 사용, 주간기능장애로 7가지 항목에 대한 평가가 가능하며, 총 19 문항으로 구성되어 있다. 각 영역별 점수는 0 점부터 3 점으로, 총 점 0-21점까지 가능하며 점수가 낮을수록 수면의 질이 좋음을 의미 하고, 8.5점 이하인 경우 '수면문제 없음, 8.5점을 초과하는 경우 '수면 문제 있음으로 분류한다.

(4) 삶의 질

삶의 질을 측정하기 위해 Ware와 Sherbourne ${ }^{32}$ 이 개발한 건강조사 축 약형(Short Form 36 Health Survey, SF-36)을 사용하였다. SF-36은 평소 및 지난 한달 간의 신체적 기능 10 문항, 신체적 역할제한 4 문항, 신체 적 통증 2 문항, 일반적 건강 5 문항, 활력 4 문항, 사회적 기능 2 문항, 감 정적 역할제한 3 문항, 정신건강 5 문항, 건강상태의 변화 1 문항으로 구 성되어 있는 설문지이다. 총 36 문항 중 건강상태의 변화에 대한 항목 을 제외하고 나머지 문항으로 건강관련 삶의 질을 평가한다. 점수계 산 방법은 각 문항의 응답에 가중치를 주어 계산하는데, 건강에 부정 적인 응답인 경우를 1점으로 하고 건강에 긍정적인 응답일 수록 2점 부터 차례로 높은 점수를 주어 점수화한 각 문항의 합산한 점수를
100 점으로 환산한다. 점수가 높을수록 삶의 질이 좋음, 점수가 낮을 수록 삶의 질이 좋지 않음으로 분류한다.

\section{3. 자료분석}

수집된 자료는 SPSS 25.0 통계 프로그램을 이용하여 다음과 같이 분 석하였다. 첫째, 연구대상자의 일반적 특성 및 코로나 19 로 인한 사회 적 거리두기 자가 평가는 기술통계(빈도 및 백분율, 평균 및 표준편 차)로 분석하였다. 둘째, 신체활동량, 수면의 질, 삶의 질 점수에 대한 연령계층별 세 그룹(20-30대, 40-50대, 60대 이상) 간의 차이는 분산분 석을 통해 비교하였으며, 다중비교를 위한 사후검정은 Bonferroni 방 법을 사용하였다. 그리고 모든 유의 수준은 0.05 로 설정하였다. 셋째, 연령계층별 세 그룹에 대한 코로나19로 인한 사회적 거리두기 스트레 스 정도, 신체활동량, 수면의 질, 삶의 질의 상관관계는 피어슨 상관계 수(r)로 분석하였다. 상관계수 값은 0.25 미만일 경우 상관성이 낮다 (little), 0.25-0.5일 경우 상관성이 보통(fair)이다, 0.5-0.75일 경우 상관 성이 중간(moderate)이다', 0.75 초과일 경우 상관성이 크다(good)'로 해석한다. ${ }^{33}$

\section{결 과}

\section{1. 연구대상자의 일반적 특성}

연구대상자 총 160 명에 대한 일반적 특성(남녀인원, 체질량지수, 나 이, 직업, 코로나 전· 후 야외활동 횟수)은 연령계층별로 나누어 표로 나타내었다(Table 1).

\section{2. 코로나19로 인한 사회적 거리두기 자가 평가}

연사회적 거리두기 준수 정도는 모든 연령계층별 그룹에서 '잘 지키 고 있다. 문항의 응답률이 가장 높았고, '잘 지키지 않는다. 문항의 응 답은 없었다. 사회적 거리두기 스트레스 정도는 연령계층 그룹별로 VAS 점수로 나타내었다(Table 2).

\section{3. 연령계층별 신체활동량, 수면의 질, 삶의 질의 점수 비교}

총 신체활동량과 $\mathrm{PSQI}$ 에 대해서 연령계층별 세 그룹 간의 유의한 차 이가 나타났으며(각 $\mathrm{p}<0.05, \mathrm{p}<0.01)$, 사후검정 결과 총 신체활동량은 20-30대 그룹과 60대 이상 그룹 간에 유의한 차이를 나타냈고, PSQI 점수는 20-30대 그룹과 60대 이상 그룹 간, 그리고 40-50대 그룹과 60 대 이상 그룹 간에 유의한 차이를 나타냈다. 삶의 질에 대해서는 세 그룹 간의 유의한차이가 없었다( $>$ >0.05)(Table 3). 


\section{4. 연령계층별 코로나19로 인한 사회적 거리두기 스트레스 정도, 신체활동량, 수면의 질, 삶의 질의 상관관계}

20-30대 그룹에서는 사회적 거리두기 스트레스 정도와 삶의 질 사이 에 통계적으로 유의한 보통의 음의 상관관계를 보였고 $(\mathrm{r}=-0.27$, $\mathrm{p}<0.05)$, PSQI와 삶의 질 사이에서도 통계적으로 유의한 보통의 음의 상관관계 $(\mathrm{r}=-0.48, \mathrm{p}<0.05)$ 를 보였다. 이는 20-30대 그룹에서는 사회 적 거리두기 스트레스가 클수록 삶의 질은 낮아짐을 의미하고, PSQI 의 점수는 높을수록 수면의 질이 좋지 않음을 의미하므로 수면의 질 Table 1. The general characteristics of subjects $(\mathrm{N}=160)$

\begin{tabular}{lrrr}
\hline & $\begin{array}{c}\text { Young } \\
\text { adults }\end{array}$ & $\begin{array}{c}\text { Middle- } \\
\text { aged adults }\end{array}$ & $\begin{array}{c}\text { Old } \\
\text { adults }\end{array}$ \\
\hline Gender & & & \\
Male & & & \\
$\quad$ Number & 26 & 17 & 32 \\
$\quad$ BMI (kg/m ${ }^{2}$ ) & 24.0 & 24.1 & 24.0 \\
Female & & & \\
$\quad$ Number & 33 & 35 & 17 \\
$\quad$ BMI (kg/m ${ }^{2}$ ) & 21.0 & 22.3 & 22.7 \\
Average age (yr) & 27.3 & 49.1 & 66 \\
Occupation (\%) & & & \\
Student & 39.0 & 0 & 0 \\
Office job & 20.3 & 7.7 & 6.1 \\
Specialized job/Technical work & 15.3 & 21.2 & 20.4 \\
Business person/Self-ownership & 3.4 & 13.5 & 14.3 \\
Service industrial employees & 1.7 & 9.6 & 10.2 \\
Housewife & 5.1 & 36.5 & 30.6 \\
Etc. & 15.3 & 11.5 & 18.4 \\
Outside activities (Number of times/Week) & & & \\
Before COVID-19 & 3.5 & 2.7 & 3.0 \\
After COVID-19 & 1.3 & 1 & 1.7 \\
\hline
\end{tabular}

BMl: Body Mass Index.
이 좋지 않을수록 삶의 질도 낮아짐을 의미한다(Table 4).

40-50대 그룹에서는 PSQI와 삶의 질 사이에서 통계적으로 유의한 중간의 음의 상관관계 $(\mathrm{r}=-0.53, \mathrm{p}<0.05)$ 를 보였다. 이는 $40-50$ 대 그룹 에서도 수면의 질이 좋지 않을수록 삶의 질도 낮아짐을 의미한다 (Table 4).

60 대 이상 그룹에서는 사회적 거리두기 스트레스 정도와 신체활 동량 그리고 PSQI 사이에 통계적으로 유의한 보통의 음의 상관관계 를 보였고(각 $\mathrm{r}=-0.35, \mathrm{r}=-0.50, \mathrm{p}<0.05$ ), 신체활동량과 PSQI 그리고 삶 의 질 사이에서도 통계적으로 유의한 보통의 양의 상관관계를 보였 다(각 $\mathrm{r}=0.30, \mathrm{r}=0.30, \mathrm{p}<0.05)$. 이는 60 대 이상 그룹에서는 사회적 거 리두기 스트레스가 클수록 신체활동량은 낮아지고 수면의 질은 높 아짐을 의미하며, 또한 신체활동량이 클수록 수면의 질은 낮아지고 삶의 질은 높아짐을 의미한다(Table 4).

\section{고 찰}

우리나라는 코로나 19 확진자 수의 지속적인 증가로 사회적 거리두기 가 더욱 철저하게 시행 중이며, 이로 인해 변화된 일상 및 환경은 개인 에게 신체적. 정신적으로 부정적인 문제를 야기할 수 있음에도 불구 하고 이를 파악하는 연령계층별 연구는 부족한 실정이다. 이러한 이 유로, 본 연구는 우리나라 국민을 대표할 수 있는 연령계층으로 대상 을 세분화시켜 코로나 19 의 장기화로 인한 포스트 코로나 시대 속에 서 변화된 신체활동량, 수면의 질, 삶의 질을 성인의 연령계층별로 비 교하고, 사회적 거리두기로 인한 스트레스와의 상관성을 분석하기 위하여 실시하였다.

현재 우리나라는 코로나 19 의 감염 및 확산을 최소화하기 위해 외 출자제 및 사회적 거리두기를 준수할 것을 강력하게 권고하고 있다. ${ }^{34}$

Table 2. Self-evaluation of social distancing by age group

$(N=160)$

\begin{tabular}{lccc}
\hline & Young adults & Middle-aged adults & Old adults \\
\hline Compliance in social distancing (Number, Percentage) & & & $35(67.30)$ \\
$\quad$ Always & $48(81.35)$ & $17(32.69)$ & $41(83.67)$ \\
Sometimes & $11(18.64)$ & 0 & $8(16.32)$ \\
Hardly & 0 & $6.13 \pm 2.26$ & 0 \\
Stress in social distancing (VAS) & $6.94 \pm 2.58$ & $7.06 \pm 1.70$ \\
\hline
\end{tabular}

VAS: Visual Analogue Scale.

Table 3. Comparison between the three groups by age for each variable

$(N=160)$

\begin{tabular}{|c|c|c|c|c|c|}
\hline & Young adults (a) & Middle-aged adults (b) & Old adults (c) & $\mathrm{p}$ & post-hoc \\
\hline Physical activity (MET-min/week) & $3,603.80 \pm 6,713.17$ & $2,232.33 \pm 4,254.98$ & $1,164.01 \pm 2,360.08$ & $0.03^{*}$ & $a>c$ \\
\hline PSQI & $6.20 \pm 2.62$ & $5.63 \pm 3.37$ & $3.94 \pm 2.98$ & $<0.01^{*}$ & $c<a, b$ \\
\hline Quality of life & $73.39 \pm 9.43$ & $70.54 \pm 10.37$ & $69.48 \pm 7.54$ & 0.06 & \\
\hline
\end{tabular}

MET: Metabolic Equivalent of Task, PSQI: Pittsburgh Sleep Quality Index.

${ }^{*} p<0.05$. 
Table 4. Correlation by age hierarchy for each variable

$(N=160)$

\begin{tabular}{|c|c|c|c|c|}
\hline Coefficient of correlation ( $r$ ) & Stress in social distancing & Physical activity & PSQI & Quality of life \\
\hline \multicolumn{5}{|l|}{ Stress in social distancing } \\
\hline Young adults & - & 0.12 & 0.23 & $-0.27^{\star}$ \\
\hline Middle-aged adults & - & -0.23 & -0.09 & 0.01 \\
\hline Old adults & - & $-0.35^{\star}$ & $-0.50^{*}$ & -0.23 \\
\hline \multicolumn{5}{|l|}{ Physical activity } \\
\hline Young adults & 0.12 & - & 0.03 & 0.02 \\
\hline Middle-aged adults & -0.23 & - & -0.03 & 0.03 \\
\hline Old adults & $-0.35^{*}$ & - & $0.30^{\star}$ & $0.30^{*}$ \\
\hline \multicolumn{5}{|l|}{ PSQI } \\
\hline Young adults & 0.23 & 0.03 & - & $-0.48^{*}$ \\
\hline Middle-aged adults & -0.09 & -0.03 & - & $-0.53^{*}$ \\
\hline Old adults & $-0.50^{*}$ & $0.30^{*}$ & - & -0.28 \\
\hline \multicolumn{5}{|l|}{ Quality of life } \\
\hline Young adults & $-0.27^{\star}$ & 0.02 & $-0.48^{*}$ & - \\
\hline Middle-aged adults & 0.01 & 0.03 & $-0.53^{*}$ & - \\
\hline Old adults & -0.23 & $0.30^{*}$ & -0.28 & - \\
\hline
\end{tabular}

PSQI: Pittsburgh Sleep Quality Index.

${ }^{*} p<0.05$.

이를 대변하듯, 본 연구에 참여한 대상자들의 주당 야외활동 횟수는 코로나 19 발생 전에 비해 코로나 19 발생 후 평균 $48.65 \%$ 감소한 것으 로 나타났으며, 대상자 총 160 명 중 $77.5 \%$ 인 124 명이 사회적 거리두기 를 잘 준수하고 있다고 응답하였다. 이와 같은 결과는 코로나 19 상황 에서 대부분의 사람들의 일상이 크게 변화했음을 시사한다. $\mathrm{Yu}^{35}$ 는 코로나 19 로 인한 '일상정지 수준'을 조사하였는데, 코로나 19 이전과 같은 일상을 100 점, 일상이 완전히 정지되거나 위축된 상황을 0 점으 로 했을 때, 평균 50 점대를 보이며 많은 사람들의 일상이 마모되고 있 음을 지적했다. 또한 경기도 공공보건의료지원단의 조사에 따르면 코로나 19 로 인한 정신건강 악화요인이 일상자유의 제한(67.5\%), 신체 활동 감소(54.3\%), 일정의 변경.취소(46.7\%) 순으로 보고되었다. ${ }^{36}$ 본 연구에서도 코로나19로 인한 스트레스 정도가 VAS점수로 평균 6.71 을 보이며 중간 이상의 스트레스를 받는 것으로 나타났다. 이것은 실 제적으로 코로나 19 감염에 대한 두려움 이외에도 장기화된 코로나 19 로 일상을 회복하지 못하는 데에 따른 것이라 볼 수 있다. 2015년 발생 한 중동호흡기증후군(메르스) 확진 환자 24 명 중 $70 \%$ 이상이 우울, 불 면 등의 정신적인 문제를 겪었고, 코로나 19 로 인한 스트레스는 메르 스의 1.5 배, 중증질환의 1.3 배 등으로 타 감염병과 비교해도 높은 수 준에 해당된다는 사실을 알 수 있었다. ${ }^{37}$

본 연구의 연령계층별 대상자들의 총 신체활동량은 20-30대, 40-50 대, 60대 이상 그룹 순으로 감소하는 것으로 나타났고, 특히 20-30대 그룹과 60 대 이상 그룹 간에는 유의한 차이를 보였다. 이는 코로나 19 의 상황임에도 신체활동량은 여전히 20-30대가 가장 높고, 60대 이상 이 가장 낮게 나타난 것이다. 노인들에게 규칙적인 신체활동은 질병
을 예방하여 노화과정을 건강하게 겪어내기 위해 굉장히 중요하지 만, 부상, 통증, 질병, 운동지식 부족, 환경제약, 경제력 등의 이유로 많 은 제약이 있는 것도 사실이다. 38,39 코로나 19 발생 전의 신체활동에 관 한 선행연구에서도 65 세 이상 그룹의 신체활동 비율은 저강도는 $41.1 \%$, 중강도는 $39.6 \%$, 고강도는 $19.3 \%$ 로 나타났고, 그에 비해 44 세 이 하 그룹은 저강도는 $35.9 \%$, 중강도는 $34.3 \%$, 고강도는 $29.8 \%$ 로 65 세 이 상 그룹이 44세 이하 그룹보다 저강도 신체활동 비율은 높고, 고강도 신체활동 비율이 낮은 것을 확인할 수 있었다. ${ }^{40}$ 대다수의 사람들은 코로나19로 인한 변화에 적응하고 있지만 사회적 거리두기 시행이 지 속될수록 신체활동량은 감소하고, 사회적 교류는 축소되어 삶의 질 이 낮아짐을 알 수 있다. ${ }^{41-43}$

본 연구에 참여한 대상자들의 직업적 특성을 보면, 20-30대 그룹은 학생 및 직장인(사무직, 전문/기술직)이 많았고, 40-50대 그룹과 60대 이상 그룹은 주부 및 직장인이 많았다. 코로나 19 로 인해 학생들은 일 시적 등교 제한으로 실시간 온라인 수업과 같은 비대면 수업이 강화 되었고, 직장인들은 재택근무와 탄력근무와 같이 노동형식이 변화 되었다. 비대면 문화가 확산되면서 야외 활동 횟수가 줄어들었고, 좌 식생활이 증가로 감소된 신체활동량을 보이며, 이로 인한 근골격계 문제를 야기시켰다. ${ }^{16,44} 40-50$ 대와 60 대 이상 그룹의 직업 중 전업주부 는 감염에 대한 불안, 24 시간 육아, 배우자의 재택근무로 인한 가정 내 생활시간 증가로 일상생활과 사회적인 접촉이 제한되면서 신체활 동량이 적어졌다. 37,45 특히, 코로나 19 로 변화된 일상 및 환경은 노인의 신체활동에 관한 동기부여와 참여율 등에 저하를 불러왔다. 노인들 의 경우 코로나 19 에 대한 염려로 몸의 크고 작은 변화에도 민감하게 
반응하게 되었으며, 대면접촉이나 집단 활동, 좁은 실내 활동이 불가 능해지다 보니 운동을 더욱 할 수 없게 만드는 제약 요인이 되었다. ${ }^{46}$ 따라서 연령대가 낮은 성인들보다 60 대 이상의 연령층을 위해 사회 적 거리두기를 준수하면서 적용이 가능한 운동프로그램의 적극적인 개발이 필요한 것으로 보인다.

본 연구의 PSQI에 대한 결과, 수면의 질은 20-30대, 40-50대, 60대 이 상 그룹 순으로 좋았고, 20-30대 그룹과 60대 이상 그룹 간, 그리고 40-50대 그룹과 60대 이상 그룹 간에 유의한 차이를 나타냈다. 코로나 이전 19-64세의 성인을 대상으로 한 연구에 따르면, 평균 PSQI 점수 가 19-39세 그룹은 5.7 \pm 2.53 점, 40-64세 그룹은 5.7 \pm 2.97 점의 결과가 나왔다. ${ }^{47}$ 이러한 결과를 본 연구의 결과와 비교해 보았을 때, 20-50대 그룹의 평균 PSQI 점수는 코로나 이전보다 조금 높아진 것을 볼 수 있고, 60 대 이상 그룹의 평균점수는 선행연구 결과보다 점수가 낮은 것을 알 수 있다. 이는 60 대 이상 그룹의 수면의 질이 코로나 19 이후 더 좋아진 반면, 20-30대 및 40-50대 수면의 질은 코로나 19 이전보다 낮아졌다는 것을 알 수 있다. 이는 노화로 인한 신체리듬과 수면패턴 의 변화로 많은 신체활동량을 하지 않아도 수면의 질에 영향을 미치 지 않는 것과 연관이 있다.48

본 연구의 연령계층별 삶의 질에서 20-30대 그룹은 79.39점, 40-50 대 그룹은 70.54점, 60대 이상 그룹은 69.48점으로 나타났지만 세 그 룹 간의 유의한 차이는 없었다. 2014년 유행했던 호흡기계 감염병인 메르스 감염에 대한 삶의 질 선행연구에서도 메르스 사태로 인해 일 반 대중이 경험한 삶의 질은 450 명 중 상'으로 응답한 비율은 54 명 (12\%), '중'으로 응답한 비율은 317명(70.4\%), '하로 응답한 비율은 79명 $(17.6 \%)$ 로 삶의 질이 크게 차이 나는 것 없이 $70 \%$ 이상의 대상자가 중 간 상태의 삶의 질을 유지하는 것을 알 수 있다. 이는 갑작스러운 재 난상황으로 삶의 질이 일시적으로 타격을 받았을지라도 정상범위에 서 크게 벗어나지 않고 항상성을 유지하려는 것을 알 수 있다.49

연령계층별 사회적 거리두기 스트레스 정도, 신체활동량, 수면의 질, 삶의 질의 상관관계를 살펴본 결과, 먼저 20-30대 그룹은 사회적 거리두기 스트레스가 높고 수면의 질이 좋지 않을수록 삶의 질이 낮 아진다는 결과를 알 수 있다. 이는 계속해서 코로나 19 확진자가 증가 하는 상황에 고용상태의 불안정함과 실업자들의 비율이 코로나 19 이전과 비해 높아지고 있고, ${ }^{21}$ 사회적 거리두기로 인해 자유로운 사회 활동이 어려워지는 것 때문이라고 볼 수 있다. 선행연구에 따르면, 거 리두기와 같은 제한적 상황과 전염병 확산에 대한 스트레스가 증가 됨에 따라 사회활동 제약과 우울 증상 간에 유의한 상관관계가 보고 되었다. 42,50 그리고 코로나 19 상황에서 삶의 질이 낮아진 성인들에게 서 사회적 거리두기로 인한 스트레스가 높게 나타났다는 선행연구들 의 결과도 이를 뒷받침한다. 10.27 또 다른 연구에서는 성인이 스트레스 를 많이 받는다면 수면의 질이 낮아진다는 결과와도 유사하다는 것
을 알 수 있다.51 더불어 좋은 수면은 일상적인 기억을 보다 긍정적으 로 이끌고 이는 부분적으로 삶의 행복에 기여한다는 선행연구를 통 해 수면의 질은 삶의 만족도와 정적인 상관관계가 있다는 것을 알 수 있다. ${ }^{52}$ 다음 40-50대 그룹은 결과적으로 수면의 질이 낮아질수록 삶 의 질도 좋지 않아짐을 알 수 있다. 한 연구에서 40-50대 성인의 업무 시간이 길어 수면의 질에 악영향을 끼친다는 결과를 도출해냈다. ${ }^{51}$ 코로나19로 인해 재택근무를 함으로써 직장에서의 업무를 집에서 하 고 있고, ${ }^{8}$ 40-50대 그룹의 업무시간이 사회적 거리두기를 전후로 큰 변화가 없다는 것은 수면의 질에 부정적인 문제를 야기한다고 말할 수 있다. 60대 이상 그룹에서는 사회적 거리두기에 대한 스트레스 정 도와 신체활동량 사이에 양의 상관성을 보이며 이는 스트레스가 클 수록 신체활동량은 낮아짐을 의미한다. 이는 사회적 거리두기로 인 한 고립과 코로나 19 감염에 대한 두려움으로 교류 단절 및 사회적 관 계 감소로 신체활동량 또한 적어짐을 말한다.43 그리고 일반적으로 잦 은 신체활동은 불면증의 발생을 낮추는 것으로 보고되고 있지만, ${ }^{53}$ 본 연구에서는 신체활동량이 낮아짐에 따라 수면의 질이 높아졌다. 본 연구에서 나타난 60 대 이상의 신체활동량을 IPAQ의 범주형 점수 로 분류했을 때 '최소한의 활동'에 속한다. ${ }^{28}$ 이것은 노인에게 있어서 격렬하거나 중등도의 신체활동보다 걷기와 근력, 유연성운동을 하는 경우에 적정 수면시간을 확보하는 비율이 높았다는 연구결과를 뒷 받침한다. ${ }^{4}$

위의 내용을 바탕으로 본 연구의 제한점은 다음과 같다. 첫째, 본 연구는 연령계층별 그룹 당 약 50 명 정도의 성인을 대상으로 한 연구 이므로 모든 성인에게 일반화하여 적용하는 것은 어렵다. 그러므로 더 많은 인원수의 연령계층별 성인을 모집하여 연구할 필요가 있다. 둘째, 본 연구에서 사용된 측정 도구는 모두 주관적인 설문지이므로 평가의 정확도에 한계가 있다. 추후 연구에서는 특히 신체활동과 수 면의 질에 있어서 객관적인 인체 측정 장비를 통한 분석으로 연구의 신뢰도와 타당도를 높일 필요가 있다. 셋째, 본 연구는 코로나19가 장 기화된 현 상황에 대한 응답만으로 평가하였으므로 코로나 19 이전 의 상황과의 비교분석은 불가능하다. 따라서 코로나 19 전후 비교가 가능한 설문문항을 추가한 연구가 필요하다. 넷째, 본 연구에서 연구 대상자의 직업 특성을 보면 20-30대 그룹에서는 학생이 많았고, 40-50 대 그룹에서는 주부의 비율이 높았다. 코로나 19 로 신체적, 정서적 피 로를 느끼고 있는 대다수의 사람들을 직업별로 구분하여 신체· 정신 적인 부분에서의 어떠한 영향을 받고 있는지 다양한 직업군의 연구 가 필요하다.

이처럼 본 연구는 코로나 19 상황에서 성인의 연령계층별로 사회적 거리두기 스트레스와 신체활동량, 수면의 질, 삶의 질에 관한 종합적 인 연구 시행을 통해 연령계층별 차이점뿐만 아니라 유사점을 함께 파악할 수 있음에 의의가 크다. 본 연구의 결과가 코로나 시대로 인한 
각 연령계층별 성인의 신체활동량, 수면의 질, 삶의 질에 대한 정보를 제공할 뿐만 아니라 포스트 코로나 시대의 신체적. 정신적 건강증진 을 위한 기초자료로 사용될 것을 기대한다.

\section{REFERENCES}

1. World health organization. Coronavirus disease (COVID-19) [Internet]. Switzerland: 2021 may 13 [cited 2021 August 26]. Available from: https:// www.who.int/news-room/q-a-detail/coronavirus-disease-covid-19.

2. Korea disease control and prevention agency. Updates on COVID-19 in republic of korea [Internet]. South Korea: 2021 July 5 [cited 2021 August 26]. Available from: http://Kdca.go.kr/board.es?mid=a20501010000\&bi $\mathrm{d}=0015 \&$ list_no $=713850 \& \mathrm{cg} \_$code $=\&$ act $=$ view\&nPage $=1$.

3. Korea disease control and prevention agency. Press release: Social distancing level 4 for the seoul metropolitan area [Internet]. South Korea: 2021 July 9 [cited 2021 August 28]. Available from: http://ncov.mohw. go.kr/tcmBoardView.do?brdId=\&brdGubun=\&dataGubun=\&ncvCon tSeq=366376\&contSeq=366376\&board_id=\&gubun=ALLhttp://Kdca. go.kr/board.es? $\mathrm{mid}=\mathrm{a} 20501010000 \& \mathrm{bid}=0015 \&$ list_no=713850\&cg code $=\&$ act $=$ view \&nPage $=1$.

4. Jefferson T, Mar CBD, Dooley L et al. Physical interventions to interrupt or reduce the spread of respiratory viruses: systematic review. BMJ. 2008; 336(7635):77-80.

5. Markel H, Lipman HB, Navarro JA et al. Nonpharmaceutical interventions implemented by US cities during the 1918-1919 influenza pandemic. JAMA. 2007;298(6):644-54.

6. Jun SH, Kim JH. Theoretical background and prospects for the untact industry. Journal of New Industry and Business. 2020;38(1):96-116.

7. Ministry of education. Press release: Digital devices not required for 1st \& 2nd graders in online classes [Internet]. South Korea: 2021 April 6 [cited 2021 August 29]. Available from: https://moe.go.kr/boardCnts/ view.do?boardID=294\&boardSeq=80214\&lev=0\&searchType=null\&st atusYN=W\&page $=1 \& s=$ moe $\& m=020402 \& o p$ Type $=\mathrm{N}$.

8. Bae YI, Shin HR. COVID-19 accelerates the untact society. Issue \& Analysis (Gyeonggi Research Institute). 2020;416:1-26.

9. Kim YJ, Park SM. Care for older adults in the era of Corona-With, what and how should be done?: based on the experiences of senior care service providers. KJSWR. 2020;67:89-121.

10. Kim JG. Cases and issues in caring for older adults using AI/robots during the COVID-19 pandemic in the US. Int Soc Secur Rev. 2021;16:1626.

11. Sa HJ, Lee WS, Lee BG. Corona blue and leisure activities: focusing on korean case. Journal of Computing and Services. 2021;22(2):109-21.

12. Shim SM. A study on non-contact classic music performances in the post-COVID-19 era: with a focus on the case of Seoul philharmonic orchestra. Ewha Womans University. Dissertation of Master's Degree. 2021.

13. Yu DG, Jeong SB, Choi SG. The analysis of differences in selection attributes of participants in online sports activities in the corona19 phenomenon. The Korean Journal of Sport. 2020;18(2):21-32.

14. Lee GI. The necessity of youth physical activity and role and task of school physical education in COVID 19. KASP. 2021;28(1):175-98.
15. Chung IJ, Lee SJ, Kang HJ. Changes in children's everyday life and emotional conditions due to the COVID-19 pendemic. Journal of Korean Society of Child Welfare. 2020;69(4):59-90.

16. Kim TH, Jee HJ, Bae CW et al. Social distancing in COVID-19: What are the implications for musculoskeletal problems and the quality of life? J Kor Phys Ther. 2021;33(2):84-90.

17. Jo SU, Shim SY, Nam SN. The effect of body composition, pulmonary function, and physical fitness in sedentary office worker by exercise. J Korean Soc Living Environ Sys. 2012;19(3):336-43.

18. Ekelund U, Besson H, Luan J et al. Physical activity and gain in abdominal adiposity and body weight: prospective cohort study in 288,498 men and women. Am J Clin Nutr. 2011;93(4):826-35.

19. Thyfault JP, Du M, Kraus WE et al. Physiology of sedentary behavior and its relationship to health outcomes. Med Sci Sports Exerc. 2015;47 (6):1301-5.

20. Park SH. Effects of employment status changes on mental health. Seoul University. Dissertation of Master's Degree. 2009.

21. Lee SB. Effects of change in employment status before/after the COVID-19 on the depression change: moderating effects of age. The Journal of Humanities and Social Science. 2021;12(3):1213-26.

22. Ministry of health and welfare. Press release: the results of the COVID-19 national mental health survey in the first quarter of 2021 [Internet]. South Korea: 2021 May 6 [cited August 29]. Available from: https:// www.mohw.go.kr/react/al/sal0301vw.jsp?PAR_MENU_ID=04\& MENU_ID=0403\&CONT_SEQ=365582.

23. An SR. COVID-19, current status and task of dealing with infectious diseases in social welfare facilities. KIHASA Health Welfare Issue Focus. 2020;381:90-100.

24. Han KR. Changes in elder's lives and death by COVID-19. Journal of Ethics. 2021;133:171-91.

25. Jeong CJ, Lee SO, Gang JH et al. A study on social support networks for each life-cycle stage of adults. J Korean Acad Soc Nurs Educ. 2012;18 (3):436-45.

26. Lee YJ, Choi GJ. The Effect of Korean Adult's Mental Health On QOL(Quality Of Life) -the fifth korea national health and nutrition examination survey, 2010. J Digit Converg. 2013;11(1):321-7.

27. Kim SY. A convergence study of stress caused by the epidemic of COVID-19, quality of life and positive psychological capital. Journal of the Korean Convergence Society. 2020;11(6):423-31.

28. Oh JY, Yang YJ, Kim BS et al. Validity and reliability of korean version of international physical activity questionnaire (IPAQ) short form. KJFM. 2007;28(7):532-41.

29. IPAQ Research Committee. Guidelines for data processing and analysis of the international physical activity questionnaire (IPAQ)-short and long forms. 2005:1-15.

30. Buysse, Daniel J, Charles F et al. The pittsburgh sleep quality index (PSQI): a new instrument for psychiatric research and practice. Psychiatry Res. 1989;28(2):193-213.

31. Sohn SI, Kim DH, Lee MY et al. The reliability and validity of the Korean version of the pittsburgh sleep quality index. Sleep Breath. 2012;16 (3):803-12.

32. Ware J, Sherbourne C. The MOS 36-Item short-form health survey (SF36): I. conceptual framework and item selection. Med Care. 1992;30 (6):473-83. 
33. Portney LG, Watkins MP. Foundations of clinical research: applications to practice. 3rd ed. Upper Saddle River, Prentice Hall, 2008:52.

34. Ministry of health and welfare. Direction of social distancing system and guidelines by social distancing level [Internet]. South Korea: 2021 June 25 [cited 2021 August 30]. Available from: http://ncov.mohw.go.kr/ searchBoardView.do?brdId=3\&brdGubun=32\&dataGubun=321\&ncv ContSeq=5587\#.

35. Yu MS. COVID-19 risk recognition and behavior. korean social trends 2020, statistics research institute, statistics korea [Internet]. South Korea: 2020 Dec 11 [cited 2021 September 3]. Available from: http://kostat. go.kr/sri/srikor/srikor_ntc/1/index.board?bmode=read\&bSeq=\&aSeq= 387035 \&pageNo=3\&rowNum $=10 \&$ navCount $=10 \&$ currPg=\&searchI nfo $=\&$ sTarget $=$ title\&sTxt $=$.

36. Gyeonggi Public Health Policy Institute. The 3rd survey on COVID-19 risk recognition in Gyeonggi-do [Internet]. South Korea: 2020 Oct 22 [cited 2021 September 5]. Available from: https://gnews.gg.go.kr/briefing/brief_gongbo_view.do?BS_CODE=S017\&number=46117.

37. Ju SJ. Effects of life changes due to COVID-19 on the mental health of children and their caregivers: focus on Busan, Korea. Journal of Korean Society of Child Welfare. 2021;70(2):67-99.

38. Gu YM, Gang JH. Study on the satisfaction of sports facilities affecting the health promotion behavior of elderly. Journal of the Korean Gerontological Society. 2015;35(1):65-78.

39. Seong CH, Yoo LK, Jang CO. Conceptual structure of exercise constraints and the difference according to the stage of change in the aged. KJSP. 2008;9(2):115-33.

40. Park SY, Yoon DH. Associations between physical activity and healthrelated quality of life in korean adults: KNHANES V-2. The Korean Journal of Physical Education. 2014;53(2):201-14.

41. Moon HJ. A phenomenological study of stress experience of college students displayed in non-face-to-face college life by COVID-19. KALCI. 2021;21(11):233-47.

42. Chon SH, Lee SH, Bae EJ et al. The college students' depressive symptoms associated with the levels of physical and social activities during the COVID-19 pandemic in South Korea: A web-based cross-sectional sur- vey. NHI. 2021;25(1):10-7.

43. Hwang MJ, Choi MJ, Bae GE et al. The various effects of social distancing on the elderly [Internet]. South Korea: 2020 Dec 23 [cited 2021 September 6]. Available from: https://www.si.re.kr/node/65054.

44. Schuch FB, Bulzing RA, Meyer J et al. Moderate to vigorous physical activity and sedentary behavior changes in self-isolating adults during the COVID-19 pandemic in Brazil: a cross-sectional survey exploring correlates. Sport Sci Health. 2021;1-9.

45. Lim YH. COVID-19 Blues: a big data analysis. The Korean Journal of Counseling and Psychotherapy. 2021;33(2):829-52.

46. Kwon OJ. A case study of changes in the exercise behavior of the elderly by COVID-19. KJSP. 2020;31(2):123-34.

47. Lee HR. Sleep quality and its associated factors in adults. J Korean Pubilc Health Nurs. 2013; 27(1):76-88.

48. Kim AR, Chae MO, Jeon HO. Effects of physical activity programs on sleep among community-dwelling elders in Korea: a systematic review and meta-analysis. JKAIS. 2018;19(3):186-97.

49. Lee DH, Kim JY, Kang HS. The emotional distress and fear of contagion related to middle east respiratory syndrome (MERS) on general public in Korea. Kor J Psychol Gen. 2016;35(2):355-83.

50. Yoon JI, Han JU, Lee JW. The relationship between the risk perception, stress level, and coping for the outdoor recreation participants during pandemic. KSLRP. 2021;45(1):89-101.

51. Choi JY, Park YM, Choi DJ et al. Factors influencing the quality of sleep in Korean adults by age groups. J East West Nurs Res. 2019;25(1):17-25.

52. Shin JE, Kim JG, Lim NY. Sleep quality and happiness among young adults: the role of positive memory bias. Korean Journal of Culture and Social Issues. 2017;23(2):271-93.

53. Jeon SN, Song HJ. The relationship between EQ-5D and optimal sleep duration among community dwelling elderly. Korean Public Health Research. 2017;43(1):13-22.

54. Shin EY. Relationships between health status, physical activity level, health related quality of life and sleep duration in the elderly. Korean Public Health Research. 2016;42(3):53-65. 